\title{
RASTREABILIDADE DE RAÇÕES A PARTIR DA ANÁLISE DAS VULNERABILIDADES E RISCOS DOS PROCESSOS
}

\author{
Alejandro Martins Rodriguez ${ }^{1}$, Ana Caroline Rodrigues Vargas ${ }^{2}$ \\ aljmartins@gmail.com ${ }^{1}$, anacarolinevargas@gmail. $\mathrm{com}^{2}$
}

\begin{abstract}
Resumo
A rastreabilidade no setor de rações reside nos aspectos da segurança alimentar, éticos e de responsabilidade comercial. Este trabalho responde a seguinte pergunta:"como propor um método de rastreabilidade em um sistema que possui muitas vulnerabilidades em seus processos?". Através do conhecimento do processo, foi possível mapeá-lo e identificar as vulnerabilidade nele existentes, e com isso definir um plano de contigência para minimizar e/ou sanar os eventos de riscos identificados. Após realizadas as melhorias, foi proposta uma abordagem de rastreabilidade.
\end{abstract}

Palavras-chave: Gestão de riscos. Vulnerabilidades no processo. Rastreabilidade.

\section{FEED TRACEABILITY FROM ANALYSIS OF PROCESS VULNERABILITY AND RISK}

\begin{abstract}
Traceability in the feed sector lies in the aspects of food safety, ethics and commercial responsibility. This paper answers the question: "How to propose a method of traceability in a system that has many vulnerabilities in its processes?". Through knowledge of the process, it was possible to map it and identify the vulnerabilities that exist in it, and thus define a contingency plan to minimize and/or remedy the identified risk events. Following the improvements, a traceability approach was proposed.
\end{abstract}

Keywords: Risk management. Process vulnerabilities. Traceability.

\section{Introdução}

Em 2014, o Brasil foi considerado o terceiro maior produtor de rações para alimentação animal no mundo, produzindo 66 milhões de toneladas, perdendo para a China, que com 183 milhões de toneladas de rações produzidas ocupou a primeira posição, e para os Estados Unidos, este que ocupando o segundo lugar, produziu 173 milhões de toneladas de ração (ALLTECH, 2015). Dessa forma, para manter essa posição ou melhorá-la perante ao mercado, é necessário que além de aperfeiçoar seus processos e oferecer produtos de qualidade, as indústrias garantam a inocuidade[ Ausência de contaminantes biológicos, químicos ou físicos no alimento, que poderiam afetar a saúde do consumidor final, causando-lhe alguma enfermidade ou lesão (RASZL, 2001).] dos seus produtos.

Revista Eletrônica do Alto Vale do Itajaí - REAVI, v.08, n 13, p. 114-124, dez 2019 ISSN: 23164190, DOI 10.5965/2316419008112019114 


\section{REAVI}

Os estabelecimentos, que fabricam fracionam, importam, exportam e comercializam rações, suplementos, premix [uma pré mistura de micro minerais e vitaminas, nesse pode conter apenas vitaminas, sendo chamado de Premix Vitamínico, ou conter apenas micro minerais, sendo, nesse caso, chamado de Premix Mineral], núcleos, alimentos para animais de companhia, ingredientes e aditivos para alimentação animal; devem possuir registros no Ministério da Agricultura, Pecuária e Abastecimento (MAPA), órgão regulador da atividade. Como meio de atender os requerimentos de mercado e exigência do MAPA, através da Instrução Normativa 4/2007 (IN 4/2007), a implantação de Boas Práticas de Fabricação (BPF) nos estabelecimentos produtores de alimentos para animais. Ter um programa de rastreabilidade está incluso na implantação das BPF.

A rastreabilidade é um método de controle que pode proporcionar respostas ao consumidor referente à segurança dos produtos. Segundo Moe (1998), a rastreabilidade tem como finalidade controlar parcialmente ou totalmente um lote do produto desde a colheita até o transporte, ou uma etapa da cadeia de produção; ou seja, rastrear uma operação ou o local em que alguma atividade ou processo foi realizado no produto.

O conceito de rastreabilidade já é conhecido, há algum tempo, por inúmeras indústrias. A que tudo indica, uma das primeiras aparições do conceito foi na década de

60 quando Morrys K. Dyer escreve um artigo sobre o controle de qualidade de sistemas espaciais da NASA (MACHADO, 2000).

A empresa em estudo, a qual será chamada de "Empresa X", foi criada no estado de Goiás, esta, que até o início da década de 1970, foi a maior produtora de arroz. Em 1972, o estado do Rio Grande do Sul começou a liderar a produção nacional de arroz e, com isso a empresa, que já realizou a tecnologia de produção e industrialização do óleo de arroz, foi atraída para a cidade de Pelotas, situada neste Estado, onde implantou sua área fabril. O farelo de arroz é adquirido dos engenhos de beneficiamento e constitui a principal matéria prima processada pela empresa, tanto para a produção de óleos vegetais quanto para a elaboração do Farelo Desengordurado de Arroz Estabilizado (FADE). O FADE é obtido através da extração do óleo do farelo bruto de arroz, além de ser um dos subprodutos comercializados pela empresa, é a principal matéria prima utilizada na fábrica de ração animal, localizada na planta. A produção de rações envolve 31 funcionários, os quais trabalham em sistema de revezamento (03 turnos de 06 horas), produzindo em torno de 2.000 toneladas/mês de rações.

Diante desse contexto, num sistema que possui diversas vulnerabilidades em seu sistema, como por exemplo, alto mix de produtos, rotatividade de mão de obra, diversidade nos insumos utilizados, sendo que alguns possuem certas restrições, torna-se claro que o problema principal desse trabalho é "Como propor um método de rastreabilidade em um sistema que possui muitas vulnerabilidades em seu processo?"

Revista Eletrônica do Alto Vale do Itajaí - REAVI, v.08, n 13, p. 114-124, dez 2019 ISSN: 23164190, DOI 10.5965/2316419008112019114 


\section{Revisão da literatura}

\subsection{Tipos de rastreabilidade}

De acordo com dados do guia GENCOD - “Traceability in the Supply Chain”, de 2000, da EAN Internacional France, uma organização internacional que estabelece padrões para definição de códigos de barra, há sete tipos diferentes de rastreabilidade (LEONELLI, 2007 apud DUARTE, 2011), listadas abaixo:

a) Rastreabilidade top-down: tem como objetivo estabelecer as relações causais ou de algum problema de qualidade. Isso se dá através de localizar, em qualquer ponto da cadeia, a origem e as características de um produto;

b) Rastreabilidade bottom-up: esse sistema objetiva a criação de um sistema de recall de produtos. Isto, pois, faz uso de um ou mais critérios de identificação, para que seja possível encontrar produtos, em qualquer ponto da cadeia produtiva;

c) Rastreabilidade upstream: através desse é possível localizar um evento ocorrido em um dentre os demais elos da cadeia produtiva a partir da descrição de procedimentos e ferramentas adotadas. Visando o estabelecimento de responsabilidade legais e físicas em torno do produto;

d) Rastreabilidade downstream: esse sistema consiste em localizar um evento ocorrido depois da transferência, a uma terceira parte, da propriedade física de produtos através da descrição dos procedimentos e ferramentas adotados;

e) Rastreabilidade interna: com esse é possível descrever o histórico das transformações e processamentos pelos quais o produto passou. Tal controle pode ser interno a uma empresa ou a toda cadeia coordenada;

f) Rastreabilidade de produto: descobrir as causas de falhas de qualidade é o objetivo deste sistema. Descobre-se através da descrição, de forma qualitativa, dos caminhos pelos quais o produto passou, assim como os procedimentos adotados em cada estágio da cadeia, além da identificação das ações tomadas em caso de inconformidade ao padrão adotado;

g) Rastreabilidade logística: neste não é necessário detalhar os procedimentos adotados, mas sim, identificar, sob o ponto de vista logístico,o caminho que o produto percorreu através da identificação das coordenadas. E assim, determinar destinos e origens para promover recalls ou retirada de produtos.

Assim, a rastreabilidade traz como consequência indireta para o mercado de alimentos uma maior comunicação entre os elos do processo e também maior interação entre o setor público e privado de produção, o que gera benefícios para a gestão e produtividade do setor (CONCHON E LOPES, 2012)

\subsection{Legislação para o setor de rações para alimentação animal}

O MAPA é o órgão responsável pela regulamentação e fiscalização do setor de produtos destinados à alimentação animal. Segundo este órgão, o estabelecimento que fabrica, fraciona, importa, exporta e comercializa rações, suplementos, premix, núcleos, alimentos para animais de companhia, ingredientes e aditivos para alimentação animal deve ser registrado no MAPA e

Revista Eletrônica do Alto Vale do Itajaí - REAVI, v.08, n 13, p. 114-124, dez 2019 ISSN: 23164190, DOI 10.5965/2316419008112019114 
observar a legislação vigente. A fiscalização destes estabelecimentos tem como principal objetivo garantir adequadas condições higiênico sanitárias nos processos de fabricação, bem como a conformidade e inocuidade dos produtos disponibilizados no mercado. E ainda a segurança e a rastreabilidade dos produtos importados e exportados (BRASIL, 2015).

Diante desse cenário, toda empresa que produz ração para alimentação animal deve seguir a IN 4/2007, que tem por objetivo definir os procedimentos básicos de higiene e de boas práticas de fabricação para alimentos fabricados e industrializados para o consumo dos animais e os registros dos produtos e estabelecimentos são realizados de acordo com as normas dispostas no Decreto 6.296/2007, que regulamenta a Lei 6.196/1974. A definição das normas para fabricação e comercialização, registro e fiscalização dos produtos destinados à alimentação animal é realizada pela Coordenação de Produtos de Alimentação Animal (CPAA), do Departamento de Fiscalização de Insumos Pecuários, da Secretaria de Defesa Agropecuária (SDA) e é executada pelos Fiscais Federais Agropecuários por meio de vistorias, fiscalizações e auditorias para verificação do atendimento da legislação.

O $7^{\circ}$ item da IN 4/2007, que trata sobre Procedimentos Operacionais Padrões (POP), descreve no item 7.1, que entre os POP que devem ser implementados, um deles é o Programa de rastreabilidade e recolhimento de produtos (Recall). Dentro dessa sessão, o item 7.13 descreve que todos os POP adotados devem registrar todas as etapas da cadeia produtiva, registro do recebimento da matéria prima, dados da produção para que em caso de não conformidade, sejam encontrados meios de saber quais as causas do problema e o responsável.

\subsection{Gestão de riscos}

Define-se como risco a possibilidade de perda decorrente de um determinado evento. A perda para a empresa significa prejuízo, lucro menor, situações em que as operações transitam pelo demonstrativo de resultados, ou redução de ativos com contrapartida no patrimônio líquido (SANTOS, 2002 apud PENHA E PARISI, 2005).

De acordo com Tomas e Alcantara (2013), a gestão de riscos tem sido um instrumento importante no que diz respeito à busca por efetiva redução de vulnerabilidades na cadeia de suprimentos. Para criar um modelo de gestão de riscos os modelos de gestão de riscos podem diferenciar-se uns dos outros, em termos de etapas que o compõem. Estas etapas são: Identificação dos Riscos, Avaliação dos Riscos, Controle dos Riscos, e Monitoramento dos riscos e avaliação do impacto da mitigação dos riscos.

\section{Etapas metodológicas e coleta de dados}

A metodologia compreendeu as seguintes etapas:

Etapa 1: Primeiramente será necessário conhecer o processo desde o recebimento de matéria prima até a expedição de produtos acabados, através de análise in loco, para que seja possível mapeá-lo e descrevê-lo;

Etapa 2: Para conhecer as vulnerabilidades existentes no processo, serão analisados os dois produtos de maior venda no penúltimo trimestre de 2015, através da análise do histórico de vendas.

Revista Eletrônica do Alto Vale do Itajaí - REAVI, v.08, n 13, p. 114-124, dez 2019 ISSN: 23164190, DOI 10.5965/2316419008112019114 
Essa escolha se deu devido a empresa possuir um alto mix de produtos. E, através da análise in loco da fabricação desses produtos, será possível conhecer as suas características, os tipos de insumos utilizados e as restrições dos mesmos;

Etapa 3: Identificação das vulnerabilidades existentes no processo e a forma com que essas podem prejudicar o sistema, a partir disso será definido um meio para que esses riscos sejam minimizados ou até mesmo sanados;

Etapa 4: Por fim, após a conclusão das etapas anteriores, as informações obtidas serão analisadas, assim como, a avaliação das restrições encontradas ao longo do estudo. Baseado nesses fatores, será proposto um método de rastreabilidade que melhor se adeque a situação da empresa.

A coleta de dados foi realizada através de observações in loco, assim como análise documental, análise de dados históricos da empresa e análise do processo. Para essa pesquisa serão coletados os seguintes dados:

- Relação dos produtos comercializados pela empresa;

- Histórico de devolução de produtos;

- Formulação das rações;

- Croqui dos produtos;

- Embalagem dos produtos;

- Rótulo dos produtos;

- Relação dos Insumos utilizados pela empresa;

- Manual de BPF da empresa.

\section{Análise e resultados}

\subsection{Vulnerabilidade nos processos}

\subsubsection{Matérias primas}

As vulnerabilidades identificadas estão representadas na Tabela 1. Tais vulnerabilidades, somadas aos fatores que as potencializam, consequentemente levam a ocorrência dos eventos de riscos.

Revista Eletrônica do Alto Vale do Itajaí - REAVI, v.08, nº 13, p. 114-124, dez 2019 ISSN: 23164190, DOI 10.5965/2316419008112019114 


\section{REAVI}

Tabela 1 - Vulnerabilidade das matérias primas e eventos de risco associados.

\begin{tabular}{|l|l|l|}
\hline Vulnerabilidades & $\begin{array}{l}\text { Fatores que podem potencializar o } \\
\text { risco }\end{array}$ & Eventos de riscos \\
\hline Matéria prima perecivel & $\begin{array}{l}\text { Não seguir a regra FIFO para os } \\
\text { insumos; } \\
\text { Na conferência dos estoques não } \\
\text { realizar a verificação das validades } \\
\text { dos insumos. }\end{array}$ & Matéria prima vencida \\
\hline $\begin{array}{l}\text { Qualidade das embalagens e o } \\
\text { manuseio dos insumos a serem } \\
\text { armazenados }\end{array}$ & $\begin{array}{l}\text { Falta de cuidado com o insumo; } \\
\text { Falta de treinamento. }\end{array}$ & \multirow{2}{*}{ Contaminação cruzada } \\
\hline $\begin{array}{l}\text { Alocação inadequada de } \\
\text { matérias primas. }\end{array}$ & $\begin{array}{l}\text { Falta de organização do espaço } \\
\text { destinado a matérias primas; } \\
\text { Inclusão de novos insumos nas } \\
\text { rações. }\end{array}$ & \\
\hline
\end{tabular}

Fonte: acervo dos autores.

Identificadas as vulnerabilidades, avaliado os riscos foram tomadas como medidas corretivas:

- Foi solicitado ao responsável do setor verificar e controlar os vencimento dos insumos, assim como, realizar o descarte dos ingredientes (ANEXO IV) que estavam com data de validade vencida. Durante essa busca constatou-se que 05 tipos de insumos ensacados encontravam-se vencidos e, 01 tipo de insumo à granel estava mofado;

- Para evitar a contaminação cruzada por contato de matéria prima com produto acabo, foi solicitado ao responsável que realizasse organização do setor e que no armazém fosse colocado uma divisória provisória até a concretização da obra de um novo espaço exclusivo para armazenar matérias primas;

- Foram realizados treinamentos com as equipes também fizeram parte da medida corretiva, onde o assunto principal foi como evitar a contaminação cruzada;

- O cuidado com os insumos foi intensificado para evitar que essa falha possa vir a se repetir. Com relação aos insumos de pouco uso, foram diminuídas as quantidades por pedido de compra por pedido para evitar perdas.

\subsubsection{Processo produtivo}

A Tabela 2 ilustra as vulnerabilidades identificadas, associadas ao processo produtivo.

Revista Eletrônica do Alto Vale do Itajaí - REAVI, v.08, nº 13, p. 114-124, dez 2019 ISSN: 23164190, DOI 10.5965/2316419008112019114 


\section{REAVI}

Tabela 2 - Vulnerabilidade no processo produtivo e eventos de risco associados.

\begin{tabular}{|l|l|l|}
\hline Vulnerabilidades & $\begin{array}{l}\text { Fatores que podem potencializar o } \\
\text { risco }\end{array}$ & Eventos de riscos \\
\hline \multirow{2}{*}{$\begin{array}{l}\text { Insumos com restrições de } \\
\text { uso }\end{array}$} & $\begin{array}{l}\text { Falha na higienização da linha; } \\
\text { Falta de treinamento. }\end{array}$ & $\begin{array}{l}\text { Contaminação da Ração A com a } \\
\text { Ração B; } \\
\text { Contaminação por insumos pode } \\
\text { ser fatal ao animal. }\end{array}$ \\
\cline { 2 - 3 } & $\begin{array}{l}\text { Mais de uma pessoa é responsável em } \\
\text { realizar a pesagem dos micro } \\
\text { ingredientes; } \\
\text { Falta de treinamento. }\end{array}$ & $\begin{array}{l}\text { Erro de pesagem de micro } \\
\text { ingredientes; } \\
\text { Mistura inadequada de micro } \\
\text { ingredientes. }\end{array}$ \\
\hline $\begin{array}{l}\text { Atualização das } \\
\text { formulações }\end{array}$ & $\begin{array}{l}\text { Ausência de algum insumo necessário } \\
\text { para produção da ração; } \\
\text { Mudanças constantes nas formulações; } \\
\text { Falta de treinamento. }\end{array}$ & Raçãa do padrão. \\
\hline
\end{tabular}

Fonte: acervo dos autores.

Diante das vulnerabilidades encontradas e com a finalidade de evitar a contaminação cruzada, foram tomadas as seguintes medidas corretivas:

- Com o intuito de diminuir a quantidade de limpeza de linha, que deve ser ocorrida a cada troca de rações, foi criado um registro de programação da produção. Nesse registro consta a ordem em que as rações devem ser produzidas, assim como suas respectivas quantidades. Sempre que possível deve-se iniciar pela produção de rações destinadas a espécies sensíveis, como por exemplo, equinos e finalizando pela produção de rações destinadas a bovinos;

- Para evitar equívocos com relação ao uso dos insumos foram criadas fichas técnicas de produto, descrevendo os insumos utilizados em determinada ração, o formato em que ela poderá ser produzida, a cor da sacaria a ser utilizada, o código do produto, o período de validade, o peso, a disposição dos sacos no palete e o tamanho da sacaria a ser utilizada;

- Devido a ocorrência constante de atualização de formulações, foi solicitado a pessoa responsável que ao enviar o relatório diário de produção por turno, fosse incluído a versão da formulação utilizada, para que a produção seja reportada no sistema tal e qual foi produzida. Há casos em que o percentual de alguns insumos muda significativamente de uma versão para outra, além da substituição de alguns insumos.

\subsubsection{Armazenagem e expedição dos produtos acabados}

A Tabela3 ilustra as vulnerabilidades encontradas na armazenagem e expedição de produtos acabados.

Revista Eletrônica do Alto Vale do Itajaí - REAVI, v.08, n 13, p. 114-124, dez 2019 ISSN: 23164190, DOI 10.5965/2316419008112019114 


\section{REAVI}

Tabela 3 - Vulnerabilidade na armazenagem e eventos de risco associados.

\begin{tabular}{|l|l|l|}
\hline Vulnerabilidades & $\begin{array}{l}\text { Fatores que podem potencializar o } \\
\text { risco }\end{array}$ & Eventos de riscos \\
\hline $\begin{array}{l}\text { Tempo de validade dos } \\
\text { produtos (120 dias). }\end{array}$ & $\begin{array}{l}\text { Falta de monitoramento diário dos } \\
\text { estoques; } \\
\text { Não cumprimento da regra FIFO; } \\
\text { Produção de produtos que possuem } \\
\text { baixo percentual de vendas; } \\
\text { Falta de treinamento. }\end{array}$ & $\begin{array}{l}\text { Possuir em estoque produtos } \\
\text { com validade vencida. }\end{array}$ \\
\hline $\begin{array}{l}\text { Produtos com nomes } \\
\text { semelhantes. }\end{array}$ & $\begin{array}{l}\text { Falta de cuidado ao carregar o produto; } \\
\text { Produtos de mesma linha, porém } \\
\text { distintos alocados no mesmo palete. }\end{array}$ & Devolução de produto. \\
\hline $\begin{array}{l}\text { Alocação inadequada de } \\
\text { matérias primas. }\end{array}$ & $\begin{array}{l}\text { Falta de organização do espaço } \\
\text { destinado a matérias primas; } \\
\text { Inclusão de novos insumos nas rações. }\end{array}$ & Contaminação cruzada. \\
\hline
\end{tabular}

Fonte: acervo dos autores.

Com a finalidade de sanar esses riscos, foram tomadas as seguintes medidas:

- Com o propósito de evitar que os produtos sejam carregados de forma equivocadas na etiqueta teste, além do nome do produto também foram acrescentados os 04 últimos dígitos do código desse;

- Foi solicitado ao responsável a organização do setor, assim como a criação de um mapa com a localização dos produtos;

- Treinamento do pessoal;

- Controle e conferência do estoque diariamente.

Revista Eletrônica do Alto Vale do Itajaí - REAVI, v.08, n 13, p. 114-124, dez 2019 ISSN: 23164190, DOI 10.5965/2316419008112019114 
Figura 1 - Modelo processual do sistema da "Empresa X".

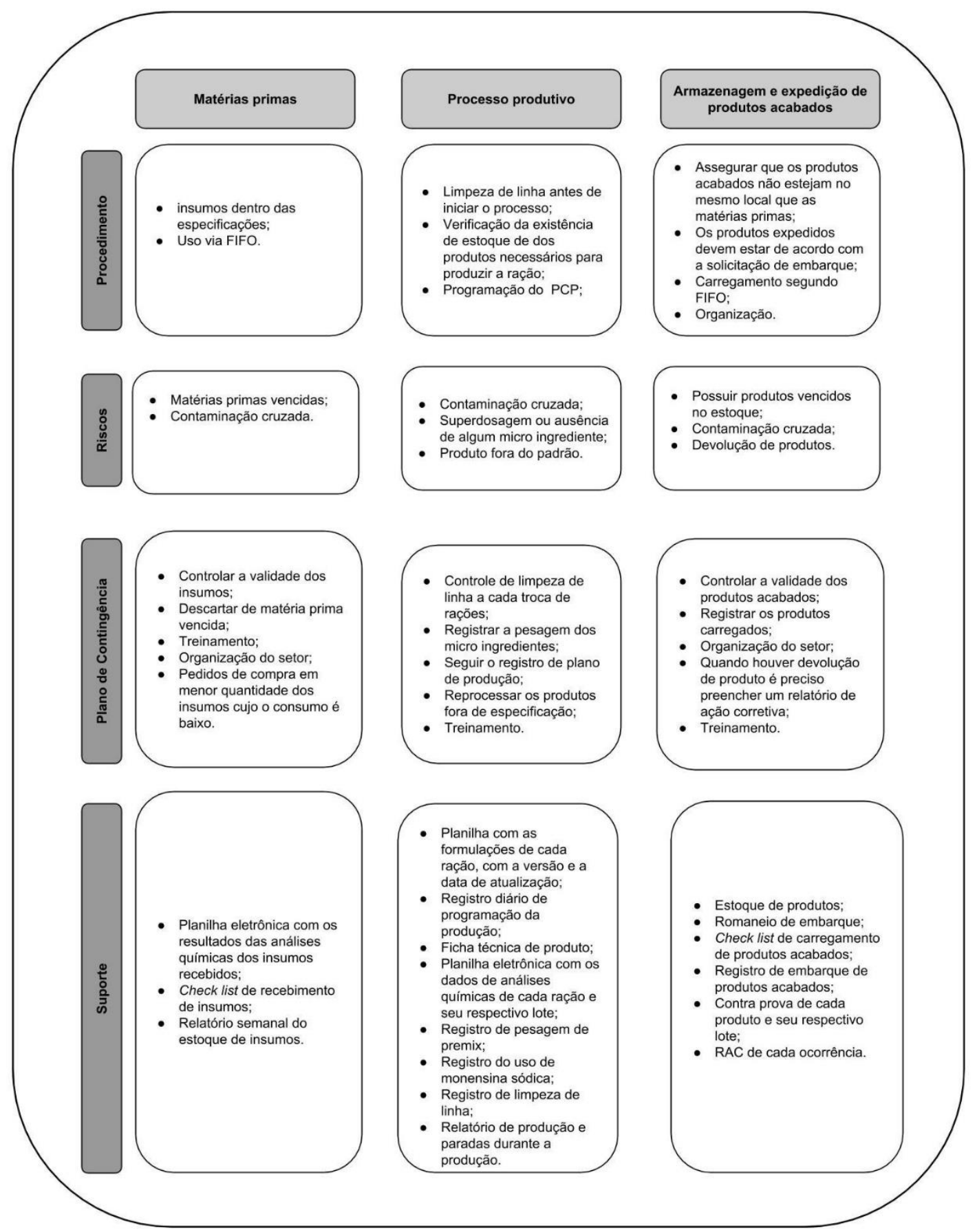

Fonte: Os autores.

Revista Eletrônica do Alto Vale do Itajaí - REAVI, v.08, nº 13, p. 114-124, dez 2019 ISSN: 23164190, DOI 10.5965/2316419008112019114 
4.2 Modelo processual do sistema

Como mencionado, os três grupos possuem vulnerabilidades, que se não tratadas podem trazer consequências negativas ao sistema (Figura 1). De maneira a melhor visualizar esses riscos, foi criado um modelo processual no qual foram descritos os seguintes itens para cada grupo:

- Procedimento: o que deve ser realizado;

- Riscos: quais os riscos que podem ocorrer;

- Plano de contingência: possui a finalidade de minimizar e/ou sanar os riscos identificados;

- Suporte: são as ferramentas que podem auxiliar no tratamento dos riscos. Os registros utilizados servem como suporte para futuras procuras e controle e conferência do que acontece em tempo real no processo.

Com esse modelo torna-se claro e de fácil entendimento o que foi discutido sobre as vulnerabilidades associadas ao processo. O que chama a atenção ao analisar o modelo é que pode ocorrer nos três grupos o risco de contaminação cruzada, porém a forma de tratá-lo é distinta para cada grupo.

\section{Considerações Finais}

Um modelo processual (Figura 1) foi criado com o propósito de expor de forma resumida e objetiva cada grupo. Os procedimentos que devem ser executados, os eventos de riscos que podem ocorrer, quais medidas foram tomadas para tratá-los e quais ferramentas são utilizadas como suporte em cada grupo. Com essas medidas alguns riscos foram minimizados, como por exemplo, ocorrência de produtos vencidos no estoque, outros até sanados, como a superdosagem dos micro ingredientes.

É importante ressaltar que a rastreabilidade é um processo crescente, irreversível, que além de ser requerido pelo mercado é exigência legal do MAPA. Além de pregar a ética e transparência nos processos de produção e distribuição dos produtos, o sistema de rastreabilidade possui características fundamentais como flexibilidade, fácil manejo, além de uma poderosa ferramenta de gestão. Essa última considerada de maior importância, porque dá aos clientes capacidade de consulta de determinado produto, e consequentemente há maior controle dos riscos. Nesse contexto, para se ter sucesso é preciso fiscalizar e ter uma vigilância vivaz, evitando assim, que as vulnerabilidades prejudiquem o sistema.

\section{REFERÊNCIAS}

ALLTECH. Alltech: 2015 Global Feed Survey. Disponível em: http://www.feedfood.com.br/wp-content/uploads/2015/03/ALLTECH-PESQUISA.pdf>. Acessado em Abril de 2015.

BRASIL. Empresa Brasileira de Pesquisa Agropecuária - Ministério da Agricultura, Pecuária e Abastecimento. Rastreabilidade na cadeia produtiva apícola. Disponível em:

Revista Eletrônica do Alto Vale do Itajaí - REAVI, v.08, nº 13, p. 114-124, dez 2019 ISSN: 23164190, DOI 10.5965/2316419008112019114 


\section{REAVI}

<http://www.cpamn.embrapa.br/apicultura/rastreabilidade.php>. Acessado em Abril de 2015.

CONCHON, Fabrício Luciano; LOPES, Marcos Aurélio. Rastreabilidade e Segurança Alimentar. Editora UFLA. Lavras - MG, 2012.

LEONELLI, Fabiana Cunha Viana; TOLEDO, José Carlos de. Rastreabilidade em cadeias agroindustriais:conceitos e aplicações. Circular Técnica 33, EMBRAPA, ISSN 1517-4778. São Carlos, SP, 2006.

MACHADO, Rosa Teresa Moreira Machado. Sinais de qualidade e rastreabilidade de alimentos: uma visão sistêmica. Organizações Rurais \& Agroindustriais, Volume 07, p. 227-237, Outubro 2005, ISSN: 2238-6890.

MOE, T. Perspectives on traceability in food manufacture, Trends in Food Science \& Technology, Volume 9, Issue 5, May 1998, Pages 211-214, ISSN 0924-2244, http://dx.doi.org/10.1016/S0924-2244(98)00037-5. Acessado em Março de 2015.

SANTOS, Paulo Sérgio Monteiro. Gestão de Riscos Empresariais: Um Guia Prático e Estratégico para Gerenciar os Riscos de sua Empresa. São Paulo: Novo Século, 2002.

PENHA, Carlos José; PARISI, Cláudio. Um caminho para integrar a gestão de risco à controladoria. In: IX Congresso Internacional de Custos, SC, 2005. Disponível em < http://www.intercostos.org/documentos/custos_97.pdf>. Acessado em Outubro de 2015.

TOMAS, Robson Nogueira; ALCANTARA, Rosane Lúcia Chicarelli. Modelos para gestão de riscos em cadeias de suprimentos: revisão, análise e diretrizes para futuras pesquisas. Gest. Prod. [online]. 2013, vol.20, n.3, pp. 695-712. ISSN 0104-530X.

Revista Eletrônica do Alto Vale do Itajaí - REAVI, v.08, n 13, p. 114-124, dez 2019 ISSN: 23164190, DOI 10.5965/2316419008112019114 